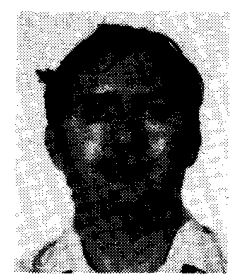

Stephen F. Sousk was born in New York City. He received the B.S. degree in mechanical engineering from Cooper Union, New York, NY, the M.S degree in aeronautical engineering from Rensselaer Polytechnic Institute, Troy, NY, and the Ph.D. in aeronautical engineering from the University of Maryland, College Park, in 1963, 1965, and 1971, respectively.

$\mathrm{He}$ is currently a Project Engineer at Belvoir RD\&E Center in Fort Belvoir, VA. He was previously employed as a Physicist in the Department of Energy (DOE) Magnetic Fusion Program and as a Mechanical Engineer in various DOE and U.S. Postal Service programs.

\section{Managers' Perceptions Towards Automation in Manufacturing}

\section{ALI F. FARHOOMAND, DENNIS KIRA AND JOHN WILLIAMS}

Abstract-In recent years, a growing number of innovation studies have focused on managers' perceptions and attitudes towards the characteristics of the innovation in order to understand future adoption behaviors in the firm. Based on a survey of managers' perceptions, this study identifies the major benefits and problems related to the adoption of new automated manufacturing systems. Variables related to cost justification are perceived to be less important than variables associated with improved flexibility and product quality in influencing a company's intention to raise its level of technological sophistication in the manufacturing area. In the same vein, problems associated with employee resistance are perceived to be less influential than variables pertaining to start up, financial justification, and system maintenance in hampering firms to raise their level of manufacturing automation. Of several organizational context variables examined in the study, only the type of industry within which the firm functions and the existence of unions in the firm appear to affect managers' perceptions of the benefits of automation. None of these moderating variables, however, seems to influence managers' perceptions of problems related to the adoption of automated manufacturing systems.

\section{INTRODUCTION}

American manufacturing firms have been under growing pressure by their Japanese counterparts to become more competitive. This competitive pressure, coupled with the recent advances in information technology, has forced an increasing number of firms to rethink the state of automation of their manufacturing systems. At the same time, academics have started to pay more attention to various issues surrounding the adoption of Advanced Manufacturing Technologies (AMT). Notably, Munro and Noori [11] have studied factors influencing the decision to automate; Meredith [8] and Meredith and Green [10] have investigated strategic planning for factory automation; Bullinger [2] has examined the role of research and development in the automation process; and Steele [14] has explained misconceptions about technology. Despite this surge of interest in the area,

Manuscript received June 30, 1989. The review of the paper was processed by Editor D. F. Kocaoglu. An earlier version of this paper was presented at the 20th Annual Meeting of the Decision Sciences Institute, New Orleans. LA, November 1989.

The authors are with Concordia University, Department of Sciences and MIS, 1455 de Maisonneuve Boulevard West, Montreal, Quebec, H3G 1M8, Canada.

IEEE Log Number 9035118. however, little attention has been paid to the role of management perceptions in the automation process (Meredith and Hill [9]). An exception is the study by Tombak and De Meyer [15], which examined the differences between attitudes of managers of firms planning to implement flexible manufacturing systems (FMS) and other manufacturing firms.

The purpose of this study is to identify the factors which influence a company's intention to raise its level of technological sophistication in the manufacturing area. The results of the study are based on a survey of managers' perceptions about and attitudes towards benefits and problems expected to arise from a change in the firm's level of manufacturing automation. Moreover, the study has investigated the role of several contextual variables (type of industry, the existing level of manufacturing automation, existence of a union in the firm, and the background of the decision maker) in the adoption process.

\section{FRAMEWORK OF THE STUDY}

A recent survey of Production (1988) showed the following results regarding managers' perceptions about the reasons behind equipment purchases:

$\begin{array}{lc}\text { Benefit } & \text { Percent Rating } \\ \text { cost reduction } & 45.5 \% \\ \text { increased capacity } & 26.0 \% \\ \text { improved quality } & 20.3 \%\end{array}$

These results were based on a survey of a broad spectrum of manufacturing firms, and are similar to those reported by Bullinger [2], who posited that managerial attitudes in America are still firmly tied to financial performance.

The problems related to straight financial justification of automation, however, have been eleborated by Kaplan [7], who maintained that increased automation may not always be cost justifiable. Justification processes for less complicated systems will be easier than those for more advanced systems. For example, the justification approach for less sophisticated systems can involve a standard economic analysis such as net present value. The new machine will simply replace an existing machine or process, and the relevant cost effects are the main concern. However, because of the flexibility of the more advanced systems in terms of their ability to introduce new product lines or to change or modify the design and manufacture of the existing products more readily, the justification for the adoption of these types of systems becomes more complex. At these levels of adoption, the justification process takes a strategic angle. The investment proposal will compete with proposals from other departments, and will be handled by the top corporate echelons. In these situations, the adoption process is influenced not only by technology push and perceived attributes of the system under study, but also by such environmental factors as pressure from competition as well as trading partners.

In order to gain a better insight into the adoption process of automated management systems, we focused on managers' perceptions about automation. In their purchasing model, Farley et al. [3] have suggested that the perceptions about automation are influenced by the current state of automation in that company. The perceived benefits and problems of automation will in turn affect the attitude towards automation. Using this model as a starting point, we predicated our study on two streams of research: 1) the theory of Reasoned Action (Fishbein and Ajzen, [5]), and 2) the model of innovation decision process (Rogers, [13]). The former theory, which examines the relationships among beliefs, attitudes and behavior, maintains that behavior is influenced by perceptions about 
the attitudes towards potential outcomes expected to result from that behavior. In another words, people's actions are systematically related to their attitudes when the nature of the attitudinal predictors and behavioral criteria are taken into consideration. In the case of technology adoption, it is posited that the intention to adopt certain automated manufacturing systems is influenced by the managers' beliefs about the potential outcomes of actually adopting an innovation, i.e., the perceived benefits and problems that could arise from that adoption.

The model of innovation decision process (Rogers, [13]), on the other hand, states that based on the perceptual characteristics of an innovation, an adopter forms a certain attitude towards that innovation during two stages of the adoption process - the persuasion stage and the confirmation stage. First, a favorable attitude would lead to a behavioral intention during the persuasion stage of the decision process. The intention to adopt could subsequently lead to an overt adoption behavior by the decision maker. One's beliefs about the characteristics of an innovation would serve as the change agent in altering one's beliefs about the outcomes of that innovation. In this context, it can be argued that the success of an innovation as perceived by the adopter (i.e., a favorable attitude towards the outcomes of the innovation) depends, among other things, on the perceived characteristics of the innovation itself. Second, attitude formation takes place in the confirmation stage of the adoption decision process when the adopters re-evaluate their attitude towards the innovation depending upon the correspondence between their prior expectations and the actual outcomes of the innovation. Potential changes could be anticipated if the total informational base underlying the attitude (Fishbein and Ajzen, [5]) were altered in the period between the persuasion and confirmation stages. A potential source of change in the decision maker's informational base is the knowledge of the outcomes of the innovation, which is a correlate of temporal setting (Fischhoff, [4]). Another important source of attitude change is active participation, which is assumed to provide the actor with an opportunity to acquire new information (Fishbein and Ajzen, [5]).

Applying these two models as a theoretical springboard, we used the taxonomy of manufacturing systems proposed by Meredith and Hill [9] in order to measure the level of sophistication of manufacturing automation in a firm. This classification divides various applications for computer-controlled production equipment into four level of complexity, ranging from stand-alone hardware that is commonly controlled by self-contained computers to fully computer-integrated manufacturing (CIM) systems that link the entire manufacturing function and all its interfaces through extensive information networks.

In implementing automated manufacturing systems, a firm will probably start with a less sophisticated system, then progressing to the more complex systems. As the complexity increases, however, the changes required in the firm's managerial outlook become even more important.

\section{MEthodology}

We measured manufacturing managers' perceptions about expected benefits and problems resulting from an increase in the firm's automation level. A questionnaire was designed using a 5-point Likert-type scale. Specifically, 13 questions elicited data pertaining to the perceived benefits of automation in such areas as cost reduction, product quality, and improved flexibility. Eighteen more questions gathered information on perceived problems related to: 1) inadequate financial justification of the system under study: 2) resistance to change; and 3 ) implementation and maintenance of the system. In addition, demographic data on the firm and the managers' experience and background were collected.
TABLE I

MEAN RATINGS OF THE PERCEIVED BENEFITS OF AUTOMATION

\begin{tabular}{ll} 
Improved Flexibility $\left(X_{1}\right)$ & 4.28 \\
Faster production & 4.00 \\
Shorter tool up & 3.28 \\
Less design time & \\
Product Quality $\left(X_{2}\right)$ & 4.60 \\
Consistent quality & 4.08 \\
Fewer rejects & 4.08 \\
Improved testing/quality assurance & 3.20 \\
Better designs & 2.84 \\
More features & \\
Cost Reduction ( $\left.X_{3}\right)$ & 3.92 \\
Lower direct labor cost & 3.56 \\
Reduced work in progress & 3.32 \\
Lower inventory & 2.92 \\
Lower fixed costs & 2.64 \\
Lower cost of materials & \\
\hline
\end{tabular}

TABLE II

MEAN DIFFERENCES BETWEEN MAJOR CATEGORIES OF BENEFITS

\begin{tabular}{crrr} 
Test & $X_{i}-X_{j}$ & \multicolumn{1}{c}{$F$} & $p$ \\
\cline { 3 - 4 } & & & \\
$\mu_{3}-\mu_{1}=0$ & -0.488 & 9.77 & 0.005 \\
$\mu_{3}-\mu_{2}=0$ & -0.581 & 11.16 & 0.003 \\
$\mu_{2}-\mu_{1}=0$ & -0.093 & 0.41 & 0.529 \\
\end{tabular}

In order to test the validity of our questionnaire, the instrument was pretested by several managers in manufacturing firms. The responses and comments of these managers were subsequently used to modify the instrument. The questionnaire was then sent out to manufacturing managers of 160 firms in Quebec and Ontario. Approximately equal numbers of questionnaires were distributed among the four categories of firms. Responses were received from 25 firms, with the following breakdown:

$\begin{array}{lr}\text { diversified large manufacturers } & 7 \\ \text { newspaper publishers and printers } & 4 \\ \text { printed circuit board firms } & 4 \\ \text { electronics firm } & 10\end{array}$

\section{RESEARCH FINDINGS}

We asked the managers to rate the importance of various variables related to each major category of benefits and problems perceived to arise from an increase in the automation level of manufacturing systems in their firm. The means and standard deviations of all variables were first calculated. Then, multivariate Hotelling's $\mathrm{T}^{2}$ test of difference in means of several variables (Johnson and Wichern [6]) was performed to see whether there are differences in the means of major factors constituting benefits and problems. Table I summarizes the mean ratings of the perceived benefits of automation.

The results of the simultaneous test of mean differences between the three major categories of perceived benefits are shown in Table II as can be seen, cost reduction is perceived to be less important than improved flexibility and product quality. No significant difference between improved flexibility and product quality was observed. These findings are different from a survey conducted by Production (1988), which reported that the major reason behind overall capital spending among American manufacturing firms is cost reduction. It should be noted that the Production's survey collected information from a broad sample of manufacturing firms, of which only $10.5 \%$ operated FMS. Our results, however, are consistent with the recent 
TABLE III

Mean Ratings of Perceived Problems with AUtOMATION

\begin{tabular}{ll}
\hline Start up and Break in $\left(X_{1}\right)$ & 3.92 \\
Design and Debugging & 3.80 \\
Integration & 3.52 \\
Software shortages & 3.40 \\
Employee training & \\
Financial Justification $\left(X_{2}\right)$ & 4.08 \\
Initial investment & 3.36 \\
Insufficient long-term benefits & 3.24 \\
Insufficient short-term benefits & 3.16 \\
Potential high future operating costs & \\
Keeping System Running $\left(X_{3}\right)$ & 4.16 \\
Finding good technical support & 3.48 \\
Bypassing when the new system is down & 2.84 \\
Possible future obsolescence & 2.80 \\
Short production runs & \\
Employee Resistance $\left(X_{4}\right)$ & 3.28 \\
From hourly workers & 2.92 \\
From factory floor management & 2.76 \\
From plant management & 2.44 \\
From production engineers & 2.36 \\
From design engineers &
\end{tabular}

TABLE IV

MEAN DIFFERENCES BETWEEN MAJOR CATEgories OF PROBLEMS

\begin{tabular}{crrr}
\hline Test & $X_{i}-X_{j}$ & $F$ & $p$ \\
\hline$\mu_{4}-\mu_{1}=0$ & -0.908 & 28.60 & 0.000 \\
$\mu_{4}-\mu_{2}=0$ & -0.708 & 9.57 & 0.005 \\
$\mu_{4}-\mu_{3}=0$ & -0.480 & 3.81 & 0.062 \\
$\mu_{3}-\mu_{1}=0$ & 0.428 & 5.51 & 0.028 \\
$\mu_{3}-\mu_{2}=0$ & 0.228 & 2.22 & 0.149 \\
$\mu_{2}-\mu_{1}=0$ & -0.200 & 1.21 & 0.281
\end{tabular}

findings of Tombak and De Meyer [15], who contended that managers are concerned with technical and economic uncertainties surrounding new adoptions, and that they consider a reduction in input variability a key issue in adopting flexible manufacturing systems.

Table III shows the mean ratings of the perceived problems of automation. The results of the simultaneous test of mean differences between the three major categories of perceived benefits are shown in Table IV.

As can be seen, the respondents perceived employee resistance to be the least serious problem arisen from an increase in the firm's manufacturing automation. This result points to a dramatic departure from the guidelines suggested in the literature (Meredith and Green, [10]) emphasizing the importance of employees' involvement in various stages of technology introduction. No statistical evidence as to the degree of importance of the other classes of problems was observed.

\section{Contextual Variables}

We also tried to investigate the role of the following contextual variables in the formation of perceptions about the benefits and problems anticipated from the introduction of a new automated manufacturing system: 1) the current level of automation in the firm; 2) the industry within which the firm operates; 3) the existence of unions in the firm, and 4) the background of managers.

We created two numerical indices for each respondent, one representing the overall perception of the benefits, the other
TABLE V

CURRENT AUTOMATION LEVEL ANALYSIS

\begin{tabular}{lrccc}
\hline Level & $n$ & Benefits Mean & Standard Deviation & $t$ \\
& 17 & 3.631 & 0.720 & 0.04 \\
Low & 8 & 3.622 & 0.360 & \\
& & & & \\
$* p<0.05$ & & &
\end{tabular}

TABLE VI

CURRENT AUTOMATION LEVEL ANALYSIS

\begin{tabular}{lrrrr}
\hline Level & $n$ & Problems Mean & Standard Deviation & $t$ \\
\hline Low & 17 & 3.274 & 0.762 & 0.02 \\
High & 8 & 3.280 & 0.721 & \\
\hline
\end{tabular}

$$
* p<0.05
$$

TABLE VII

INDUSTRY ANALYSIS

\begin{tabular}{|c|c|c|c|c|}
\hline Category & $n$ & Benefits Mean & Standard Deviation & $t$ \\
\hline Electronics & 14 & 3.894 & 0.560 & $2.73 *$ \\
\hline Nonelectronics & 11 & 3.291 & 0.537 & \\
\hline
\end{tabular}

$* p<0.05$

pertaining to the overall perception of the problems related to new adoptions. Using t-test we investigated the role of each of the four moderating variables in the adoption process.

\section{1) Current Automation Level}

According to the model of buying behavior presented by Farley et al. [3], the current state of automation in a firm influences managers' perceptions of benefits and problems of automation. We tried to investigate this proposition by comparing the perceived benefits and problems among firms in different levels of manufacturing automation. Due to small sample size, we lumped firms identifying themselves to be in level 1 and level 2 of manufacturing system (Meredith and Hill, [9]) in one group (low), and firms in level 3 or level 4 in another group (high).

Hypothesis 1(a): There are no significant differences in the perceived benefits of increased automation level between managers of highly automated and less automated firms. (See Table V.)

Hypothesis 1(b): There are no significant differences in the perceived problems of increased automation level between managers of highly automated and less automated firms. (See Table VI.)

As can be seen no difference in either perceived benefits or problems between managers of highly automated and less automated firms were observed.

\section{2) Industry Within which the Firm Operates}

A major problem surrounding innovation studies is the confounding effect resulting from the type of industry (Rogers, [13]). We tried to circumvent this problem by dividing our sample into two groups: electronics and nonelectronics firms.

Hypothesis 2(a): There are no significant differences in the perceived benefits of increased automation level between managers of electronics and nonelectronics firms. (See Table VII.)

Hypothesis 2(b): There are no significant differences in the perceived problems of increased automation level between managers of electronics and nonelectronics firms. (See Table VIII.) 
TABLE VIII

INDUSTRY ANALYSIS

\begin{tabular}{lcccc}
\hline Category & $n$ & Problems Mean & Standard Deviation & $t$ \\
\hline Electronics & 14 & 3.419 & 0.606 & 1.14 \\
Nonelectronics & 11 & 3.094 & 0.814 & \\
\hline
\end{tabular}

$* p<0.05$

TABLE IX

UNION STATUS ANALYSIS

\begin{tabular}{lcccc}
\hline Category & $n$ & Benefits Mean & Standard Deviation & $t$ \\
\hline Nonunion & 13 & 3.400 & 0.630 & $2.06^{*}$ \\
Union & 12 & 3.876 & 0.524 & \\
\hline
\end{tabular}

$* p<0.05$

TABLE $X$

UNION STATUS ANALYSIS

\begin{tabular}{lcccc}
\hline \hline Category & $n$ & Problems Mean & Standard Deviation & $t$ \\
\hline Nonunion & 13 & 3.085 & 0.763 & 1.39 \\
Union & 12 & 3.483 & 0.672 & \\
\hline
\end{tabular}

$* p<0.05$

As can be seen, the electronic firms perceive the benefits of automation to be higher than nonelectronics firms. A possible explanation could be that the managers in the electronics industry are generally more familiar with technological developments than their counterparts in nonelectronics firms. Moreover, because the products manufactured in electronics firms are usually complex, these firms see more readily the potential benefits of automation than do nonelectronics firms. No significant difference in perceived problems between managers of electronics and nonelectronics firms was observed.

\section{3) Existence of Unions in the Firm}

Historically, firms with a unionized labor forces have approached automation differently than nonunionized firms. On the one hand, unions have tried to ensure job security in the wake of automation. On the other hand, firms have tried to reap the benefits of automation in terms of reduced workforce and increased flexibility in manufacturing systems (Meredith and Green, [10]).

Hypothesis 3(a): There are no significant differences in the perceived benefits of increased automation level between managers of firms with unionized work forces and those in firms with no unions. (See Table IX.)

Hypothesis 3(b): There are no significant differences in the perceived problems of increased automation level between managers of firms with unionized work forces and those in firms with no unions. (See Table X.)

These findings are not surprising in light of the historical contractual difficulties between management and unions in North America. The benefits of increased flexibility are perceived by managers to be important because unions have traditionally tended to make a firm's production process less flexible. Also, an economic explanation of this finding might be found in the differences in labor costs in unionized versus nonunionized firms. In this context, it appears that the popular belief that automation would entail a
TABLE XI

UNION STATUS ANALYSIS-EMPLOYEE RESISTANCE

\begin{tabular}{|c|c|c|c|c|}
\hline Category & $n$ & $\begin{array}{l}\text { Resistance } \\
\text { Mean }\end{array}$ & Standard Deviation & $t$ \\
\hline Union & 13 & 3.317 & 1.080 & $2.54 *$ \\
\hline Nonunion & 12 & 2.231 & 1.058 & \\
\hline
\end{tabular}

$$
* p<0.05
$$

TABLE XII

MANAGER BACKGROUND ANALYSIS

\begin{tabular}{lcccc}
\hline & & & & \\
\hline Category & $n$ & Benefits Mean & Standard Deviation & $t$ \\
\hline Engineering & 14 & 3.656 & 0.676 & $0.25^{*}$ \\
Nonengineering & 11 & 3.594 & 0.569 & \\
\hline
\end{tabular}

$$
* p<0.05
$$

TABLE XIII

MANAGER BACKGROUND ANALYSIS

\begin{tabular}{lcccc}
\hline Category & $n$ & Problems Mean & Standard Deviation & $t$ \\
\hline Engineering & 14 & 3.318 & 0.697 & 0.31 \\
Nonengineering & 11 & 3.223 & 0.811 & \\
\hline
\end{tabular}

$$
* p<0.05
$$

reduction in workforce (Meredith and Green, [10]) is stronger among managers in firms with unionized labor than among their counterparts in companies with nonunionized workforce.

In addition to these two major findings, we compared the degree of resistance to change in unionized versus nonunionized firms.

Hypotheses 3(c): There are no significant differences in the perceived resistance to change between managers of firms with unionized work forces and those in firms with no unions. (See Table XI.)

Managers in firms with unionized work force appear to expect to encounter greater degrees of resistance caused by introduction of new technologies than do their counterparts in non-unionized firms.

\section{4) Background of Managers}

The final set of hypotheses relates to the potential confounding effect of the educational background of the respondents on their perceptions of benefits and problems of automation.

Hypothesis 4(a): There are no significant differences in the perceived benefits of increased automation level between managers with engineering and nonengineering backgrounds. (See Table XII.)

Hypothese 4(b): There are no significant differences in the perceived problems of increased automation level between managers with engineering and nonengineering backgrounds. (See Table XIII.)

As can be seen, no significant difference between managers with engineering background and those with nonengineering backgrounds was observed.

\section{CONCLUSION}

In this study, we attempted to examine management perceptions towards the benefits and problems of automated manufacturing systems. Our results indicated that managers perceive cost reduction to be a less important benefit arising from an increase in the firm's manufacturing automation than improved flexibility and product 
quality. Similarly, problems related to employee resistance are believed to be less significant than problems associated with start-up and break-in, financial justification, and system maintenance.

Apart from the degree of importance of various benefits and problems, we also examined the role of four organizational context variables in the adoption process. We found that the existence of unions and the type of industry appear to affect the managers' perceptions of the benefits of manufacturing automation. None of these moderating variables, however, seems to influence the managers' perceptions of the related problems.

It is recognized that the results of this study are somewhat attenuated because of the small sample size and problems related to perceptual studies. However, given the extreme importance of managers' perceptions and attitudes in the technology adoption decision process (Rogers, [13]), this study has shed some light on the major factors that influence or hamper this process.

Based on our review of literature as well as the feedback we received from several managers during the pretesting of the survey questionnaire, we have identified four major problems which have impeded research in the area of manufacturing adoption process: 1) a lack of consensus as to what constitutes AMT success; 2) diversity of different types of AMT used in different contexts; 3) difficulties in measuring the qualitative benefits of AMT, and; 4) complexities involved in bringing different stakeholders' perceptions of AMT success in unison.

As a growing number of firms adopt various technologies because of strategic reasons rather than mere economic considerations, we need to address these issues. The development of an all-encompassing framework for the evaluation of AMT effectiveness is obviously a logical first step. Subsequently, we need to focus on design and development of instruments which can validly and reliably capture and operationalize the attributes which lead to the effectiveness of AMT. It is only then that we can further highlight our understanding of the issues surrounding automated manufacturing systems.

\section{REFERENCES}

[1] I. Ajzen and M. Fishbein, "Attitude-behavior relations: A theoretical analysis of review of empirical research," Psychological Bulletin, pp. 888-918, 1977.

[2] H. J. Bullinger, et al. "Toward the Factory of the Future," Intl. Jnl. of Prod. Research, vol. 24, no. 4, pp. 105-35, 1986.

[3] J. Farley, et al. "Modeling the Choice to Automate," Sloan Management Review, pp. 5-15, winter, 1987.

[4] B. Fischhoff, "The Effect of Temporal Setting on Likelihood Estimates," Organizational Behaviour and Human Performance, vol. 15, pp. 180-194, 1976.

[5] M. Fishbein and I. Ajzen, Beliefs, Attitude, Intention, and Beha viour: an Introduction to Theory and Research. Reading, MA Addison Wesley, 1975.

[6] R. A. Johnson and D. W. Wichern, Applied Multivariate Statistical Analysis. Englewood Cliffs, NJ: Prentice-Hall, 1988

[7] R. S. Kaplan, "Yesterday's accounting undermines production," Harvard Business Review, pp. 95-101, 1984.

[8] J. R. Meredith et al., "Justifying techniques for AMT's," Int. Jnl. Prod. Research, vol. 24, no. 5, pp. 1043-57, 1986.

[9] J. Meredith and M. Hill, "Justifying new manufacturing systems: A managerial approach," Sloan Management Review, pp. 49-61, 1987.

[10] J. Meredith and S. Green, "Managing the introduction of advanced manufacturing technologies," Manufacturing Review, vol. 1, no. 2 , pp. 87-92, 1988.
[11] $\mathrm{H}$. Munro and $\mathrm{H}$. Noori "Measuring commitment to New Manufacturing Technology: Integrating Technological Push and Marketing Pull Concepts," IEEE Trans. Eng. Manag., vol. 35, no. 2, pp. 63-70, 1988.

[12] "Capital spending," Production, pp. 38-45, Jan. 1988

[13] E. Rogers, Diffusion of Innovations. New York: Free Press, 1983.

[14] L. Steele, "Managers' misconceptions about technology," Harvard Business Reveiw, pp. 133-140, 1983

[15] M. Tombak and A. De Meyer, "Flexibility and FMS: An empirical analysis," IEEE Trans. Eng. Manag., vol. 35, no. 2, pp. 101-107, 1988.

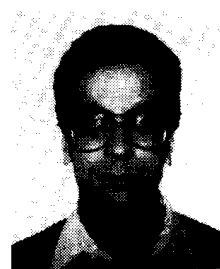

Ali F. Farhoomand received the B.Eng and M.B.A. degrees from McGill University, Montreal, $\mathrm{PQ}$, Canada, and is presently pursuing his doctoral degree in MIS at McGill.

He is currently an Assistant Professor of Management Information Systems and Director of Faculty Information Systems, Faculty of Commerce and Administration at Concordia University, Montreal, $P Q$, Canada, where he is involved in research studies related to adoption and assessment of information technology. His writings have appeared in various journals, including MIS Quarterly, Database, Journal of Information Systems Management, Datamation, and American Journal of Small Business. $\mathrm{He}$ is also a Doctoral Fellow of the Society for Information Management, and a member of the Association for Computing Machinery, TIMS, and the Decision Sciences Institute.

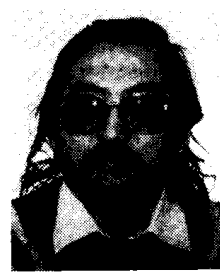

Dennis Kira received the B.Sc. and M.Sc. degrees in mathematics from Simon Fraser University, Burnaby, BC, Canada, and the Ph.D. degree in management Science from the University of British Columbia, Vancouver, BC, Canada.

$\mathrm{He}$ is presently an Associate Professor in the Department of Decision Sciences and MIS at Concordia University, Montreal, PQ, Canada. He has published articles in publications such as Management Science, the Review of Economic Studies, Omega, the Journal of Environmental Economics and Management, Managerial and Decision Economics, IEEE TRANSACTIONS ON ENGINEERING MANAGEMENT, Journal of Business and the Decision Making Under Uncertainty. His research interests include DSS, stategic Planning models, financial modeling, and the choice models. He is a member of TIMS, CORS, and DSI.

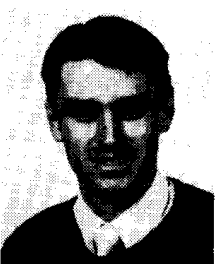

John H. Williams received the B.Sc. degree (with honors) in electrical engineering from Queen's University, Kingston, ON, Canada, and the MBA degree from Concordia University, Montreal, PQ, Canada, in 1984 and 1988, respectively.

From 1984 to 1986 he worked as a Hardware Design Engineer for Securiplex Systems, Montreal, developing naval communications systems. $\mathrm{He}$ is presently a Management Consultant with Moneco Limited, Montreal. 